\title{
Astroglial tracer BU99008 detects multiple binding sites in Alzheimer's disease brain
}

\author{
Amit Kumar ${ }^{1,2} \cdot$ Niina A. Koistinen ${ }^{1} \cdot$ Mona-Lisa Malarte ${ }^{1} \cdot$ Inger Nennesmo ${ }^{3} \cdot$ Martin Ingelsson $^{4} \cdot$ \\ Bernardino Ghetti $\mathbb{1}^{5} \cdot$ Laetitia Lemoine ${ }^{1} \cdot$ Agneta Nordberg $\mathbb{B}^{1,6}$
}

Received: 8 January 2021 / Revised: 17 March 2021 / Accepted: 1 April 2021 / Published online: 23 April 2021

(C) The Author(s) 2021. This article is published with open access

\begin{abstract}
With reactive astrogliosis being established as one of the hallmarks of Alzheimer's disease (AD), there is high interest in developing novel positron emission tomography (PET) tracers to detect early astrocyte reactivity. BU99008, a novel astrocytic PET ligand targeting imidazoline-2 binding sites $\left(\mathrm{I}_{2} \mathrm{BS}\right)$ on astrocytes, might be a suitable candidate. Here we demonstrate for the first time that BU99008 could visualise reactive astrogliosis in postmortem AD brains and propose a multiple binding site [Super-high-affinity (SH), High-affinity (HA) and Low-affinity (LA)] model for BU99008, $\mathrm{I}_{2}$ BS specific ligands (2-BFI and BU224) and deprenyl in $\mathrm{AD}$ and control $(\mathrm{CN})$ brains. The proportion (\%) and affinities of these sites varied significantly between the BU99008, 2-BFI, BU224 and deprenyl in AD and CN brains. Regional binding studies demonstrated significantly higher ${ }^{3} \mathrm{H}-\mathrm{BU} 99008$ binding in $\mathrm{AD}$ brain regions compared to $\mathrm{CN}$. Comparative autoradiography studies reinforced these findings, showing higher specific binding for ${ }^{3} \mathrm{H}$-BU99008 than ${ }^{3} \mathrm{H}$-Deprenyl in sporadic AD brain compared to $\mathrm{CN}$, implying that they might have different targets. The data clearly shows that BU99008 could detect $\mathrm{I}_{2} \mathrm{BS}$ expressing reactive astrocytes with good selectivity and specificity and hence be a potential attractive clinical astrocytic PET tracer for gaining further insight into the role of reactive astrogliosis in AD.
\end{abstract}

Supplementary information The online version contains supplementary material available at https://doi.org/10.1038/s41380021-01101-5.

Agneta Nordberg

Agneta.K.Nordberg@ki.se

1 Division of Clinical Geriatrics, Center for Alzheimer Research, Department of Neurobiology, Care Sciences and Society, Karolinska Institutet, Stockholm, Sweden

2 Department of Physics and Astronomy, Uppsala University, Uppsala, Sweden

3 Department of Pathology, Karolinska University Hospital, Stockholm, Sweden

4 Department of Public Health and Caring Sciences, Geriatrics, Uppsala University, Uppsala, Sweden

5 Department of Pathology and Laboratory Medicine, Indiana University School of Medicine, Indianapolis, IN, USA

6 Theme Aging, Karolinska University Hospital, Stockholm, Sweden

\section{Introduction}

Amyloid plaques, neurofibrillary tangles but also neuroinflammatory markers such as aberrant astrocytes and microglia are considered to play an important role in the pathophysiological processes characterising the development of Alzheimer's disease (AD). Astrocytes represent the $20-40 \%$ population of glial subtype-cells in the CNS and perform a wide array of functions needed for an optimal brain functioning and homeostasis [1-5]. In general, the human brain has an average of $50 \%$ of glial cells, but in the cerebral cortex, they account for $80 \%$ of the cells, whereas in the cerebellum, glia cells account for around 20\% [6]. Moreover, they play a crucial role in regulating homeostasis of glutamate and $\gamma$-aminobutyric acid (GABA) transport through glutamate/GABA-glutamine shuttle $[4,7,8]$ and can also induce synaptic plasticity and boost memory formation, as recently demonstrated $[9,10]$. Most importantly, they respond to CNS insults/injuries and disease state by a specific defense process called reactive astrogliosis $[11,12]$. According to a newly published consensus statement, reactive astrogliosis should be defined as the process where astrocytes engage in molecularly defined programs 
involving changes in transcriptional regulation, as well as biochemical, morphological, metabolic, and physiological remodeling, which ultimately result in gain of new function (s) or loss or upregulation of homeostatic ones [13]. Several recent studies have implicated reactive astrocytes mediated neuroinflammation in the etiology of $\mathrm{AD}$ and other neurological disorders [7, 14-17]. Postmortem studies have shown that reactive astrocytes are closely associated with amyloid- $\beta$ plaques and tau (neurofibrillary tangles) in the cortical and hippocampal regions of AD brain [18-21]. Moreover, reactive astrocytes can undergo morphological changes and upregulate the production of glial fibrillary acidic proteins (GFAP) [11] and promote the release of inflammatory mediators such as cytokines (interleukin (IL)$1 \mathrm{~b}$ and IL-6) and tumour necrosis factor-alpha [22], thereby triggering/promoting neuroinflammation as observed in $\mathrm{AD}$ [16, 17, 23, 24].

With recently published studies supporting the notion that reactive astrogliosis-mediated-neuroinflammation could precede other pathological hallmarks of $\mathrm{AD}$ during the early-stages of disease progression [15, 16, 25-29], there is a great need of developing novel astrocytic PET-tracers to monitor the function and in vivo distribution of astrocytes. So far only few PET-tracers targeting astrogliosis have been tested including ${ }^{11} \mathrm{C}$-deutrium-L-deprenyl $\left({ }^{11} \mathrm{C}\right.$-DED), which targets the monoamine oxidase $\mathrm{B}$ (MAO B) enzyme $[30,31] .{ }^{11} \mathrm{C}$-DED PET studies have been shown to be useful for visualising reactive astrogliosis in several chronic brain diseases such as epilepsy, Creutzfeldt-Jakob disease and amyotrophic lateral sclerosis [32-35].

We have previously demonstrated a high degree of reactive astrogliosis $\left({ }^{11} \mathrm{C}\right.$-DED PET) in patients with mild cognitive impairment (MCI; amyloid positive [27] as well as in pre-symptomatic autosomal-dominant Alzheimer's disease (ADAD) cases [36, 37]. We showed a negative correlation between reactive astrogliosis and amyloid plaque load and a positive correlation between ${ }^{11} \mathrm{C}$-DED and ${ }^{18} \mathrm{~F}$-deoxyglucose uptake in ADAD cases suggesting that reactive astrogliosis is implicated in the initial stages of $\mathrm{AD}$ progression [37, 38]. Our immunostaining and autoradiography studies using ${ }^{3} \mathrm{H}$-Deprenyl have highlighted tight interconnection between tau pathology and reactive astrogliosis by demonstrating similar laminar cortical distribution for AT8 (tau) and GFAP antibody staining as well as for ${ }^{3} \mathrm{H}$-THK5117 and ${ }^{3} \mathrm{H}$-DED radiotracers in AD cases [39], including carriers of Arctic mutation in the amyloid- $\beta$ precursor protein (ABPParc) [40]. These studies suggested good reliability of ${ }^{11} \mathrm{C}$-DED as an astrocytic tracer, however, there is still a high interest in developing more specific astrocytic PET-tracers and markers for reactive astrogliosis as MAO B expression is not limited to reactive astrocytes but is also observed in non-reactive astrocytes and in serotonergic, histaminergic [41] and cholinergic [42] neurons.
Tyacke et al. identified a new PET-tracer called ${ }^{11} \mathrm{C}$ BU99008, specifically and selectively targeting outer mitochondrial imidazoline ${ }_{2}$ binding sites $\left(\mathrm{I}_{2} \mathrm{BS}\right)$ that are predominantly expressed in astrocytes but also localised in neurons, albeit in a much lower density [43-46]. It is important to consider that the properties of $\mathrm{I}_{2} \mathrm{BS}$ can vary at molecular level between astrocytes and neurons as they represent a group of biologically diverse heterogenous proteins (molecular weight $\sim 30, \sim 45-55, \sim 66, \sim 85 \mathrm{kDa}$ ) and the expression level of these receptor proteins can vary depending on the pathology [44]. Previous studies have shown a parallel link between $\mathrm{I}_{2} \mathrm{BS}$ and GFAP levels in $\mathrm{AD}$ brain [47] and have suggested a direct physiological role for $\mathrm{I}_{2} \mathrm{BS}$ in the regulation of GFAP expressions [48]. Upregulation of $\mathrm{I}_{2} \mathrm{BS}$ density has been seen in psychiatry disorders such as depression [49]. Most importantly, Ruiz et al. already in 1993 demonstrated by using mixed $\mathrm{I}_{2} \mathrm{BS} / \alpha 2$ adrenoceptor inhibitor ${ }^{3} \mathrm{H}$-idazoxan a $63 \%$ increase in $\mathrm{I}_{2} \mathrm{BS}$ density in $\mathrm{AD}$ postmortem brain tissues [50], which further indicated that it could serve as an reliable surrogate marker to specifically visualise and monitor astrocyte (glial) activation in the human brain during normal and disease states.

Even though the animal preclinical studies [45, 46, 51] and the first human ${ }^{11} \mathrm{C}$-BU99008 PET-study in healthy volunteers demonstrated high specificity and selectivity for $\mathrm{I}_{2} \mathrm{BS}$, good brain penetration and biodistribution for the tracer [43], no binding/comparative studies for BU99008 in $\mathrm{AD}$ cases are available so far to the best of our knowledge. The aim of this study was therefore to evaluate and compare the binding behaviour of the $\mathrm{I}_{2} \mathrm{BS}$ astrocytic PET tracer BU99008 in postmortem control (CN) and AD brain tissue using in vitro binding studies in order to estimate its potential as a novel astrocytic PET tracer for future clinical use and to compare it with $\mathrm{I}_{2} \mathrm{BS}$-specific ligands (2-BFI and BU224) and the established astrocytic PET tracer deprenyl. We also aimed to compare ${ }^{3} \mathrm{H}$-BU99008 and ${ }^{3} \mathrm{H}$-Deprenyl binding behaviour in $\mathrm{CN}$ and sporadic $\mathrm{AD}$ tissue from large frozen human brain sections in a head-to-head in vitro autoradiography analysis.

\section{Materials and methods}

\section{Chemicals}

${ }^{3} \mathrm{H}-\mathrm{BU} 99008$ (specific activity $(\mathrm{SA})=83 \mathrm{Ci} / \mathrm{mmol}$ ), ${ }^{3} \mathrm{H}-\mathrm{L}-$ Deprenyl $(\mathrm{SA}=84 \mathrm{Ci} / \mathrm{mmol})$ and unlabelled BU99008 were custom synthesised by Novandi Chemistry $A B$ (Södertälje, Sweden). Unlabelled (R)-(-)-Deprenyl was purchased from Tocris Bioscience. The $\mathrm{I}_{2} \mathrm{BS}$ specific ligands 2-(4,5-Dihydroimidazol-2-yl)quinoline hydrochloride (BU224) and 2-(Benzofuran-2-yl)-2-imidazoline hydrochloride (2-BFI), the reversible MAO B inhibitor 
safinamide and all other chemicals (sodium chloride $(\mathrm{NaCl})$, potassium chloride $(\mathrm{KCl})$, calcium chloride $\left(\mathrm{CaCl}_{2}\right)$, Tris base, magnesium chloride $\left(\mathrm{MgCl}_{2}\right)$, disodium phosphate $\left(\mathrm{Na}_{2} \mathrm{HPO}_{4}\right)$ and potassium dihydrogen phosphate $\left(\mathrm{KH}_{2} \mathrm{PO}_{4}\right)$ ) were purchased from Sigma-Aldrich AB, Sweden.

\section{Autopsy material}

Human frozen brain tissue from six AD patients and seven CNs was provided by the Netherlands Brain Bank, Amsterdam, Netherlands (see Table 1. for clinical demographic data). The brain homogenates were prepared in $1 \mathrm{X}$ PBS buffer ( $\mathrm{pH} 7.4$ ) containing $0.1 \%$ BSA and protease/ phosphatase inhibitors and were stored at $-80^{\circ} \mathrm{C}$ in aliquotes until use in binding experiments.

Large frozen whole right hemisphere brain tissue from one $\mathrm{CN}$ patient was provided by the Neuropathology of Dementia Laboratory, Indiana University School of Medicine, Indianapolis, IN, USA. Large frozen left hemisphere brain tissue from one patient with sporadic AD was provided by the Brain Bank at Karolinska Institutet and a large frozen left hemisphere brain tissue from one A $\beta$ PParc carrier was provided by the Uppsala University brain bank. Refer to Table 1. for clinical demographic data of these cases. Direct comparisons between the cases should be taken with caution due to the fact that the large frozen sections were not from exactly the same coronal anatomical level.

\section{Saturation binding assays}

The saturation binding assay was performed by incubating postmortem temporal cortex brain homogenate $(0.1 \mathrm{mg}$ tissue) from one $\mathrm{CN}$ and $\mathrm{AD}$ patient with increasing concentration of ${ }^{3} \mathrm{H}-\mathrm{BU} 99008(0-35 \mathrm{nM})$ in $50 \mathrm{mM}$ Tris- $\mathrm{HCl}$ binding buffer $\mathrm{pH} 7.4(50 \mathrm{mM}$ Tris-base, $140 \mathrm{mM} \mathrm{NaCl}$, $1.5 \mathrm{mM} \mathrm{MgCl}_{2}, 5 \mathrm{mM} \mathrm{KCl}, 1.5 \mathrm{mM} \mathrm{CaCl}_{2}$ ) at $37^{\circ} \mathrm{C}$ for $1 \mathrm{~h}$. Non-specific (NSP) binding was determined with $1 \mu \mathrm{M}$ unlabelled BU99008. The binding reaction was terminated by filtering through glass fiber filters (pre-soaked for $2-3 \mathrm{~h}$ in $0.3 \%$ polyethylenimine), followed by three quick rinses with cold binding buffer and overnight incubation of the filter in the scintillation liquid. The radioactivity in the tubes

Table 1 Clinical demographic data for subjects used in this study.

\begin{tabular}{|c|c|c|c|c|c|c|}
\hline & $\operatorname{Sex}(M / F)$ & Age (years) & Braak stage & ApoE (E/E) & Onset & $\begin{array}{l}\text { Postmortem delay } \\
\text { (hr:minutes) }\end{array}$ \\
\hline \multicolumn{7}{|l|}{ For binding studies } \\
\hline \multirow[t]{8}{*}{ Control } & $\mathrm{F}$ & 50 & 1 & $3 / 3$ & N/A & $4: 10$ \\
\hline & M & 62 & 1 & $3 / 3$ & N/A & $7: 20$ \\
\hline & $\mathrm{F}$ & 71 & 1 & $3 / 2$ & N/A & $7: 10$ \\
\hline & $\mathrm{F}$ & 77 & 1 & $3 / 3$ & N/A & $2: 55$ \\
\hline & M & 78 & 1 & $3 / 3$ & N/A & $<17: 40$ \\
\hline & M & 79 & 2 & $3 / 3$ & N/A & 9:00 \\
\hline & $\mathrm{F}$ & 84 & 1 & $3 / 3$ & N/A & $6: 55$ \\
\hline & $3 \mathrm{M} / 4 \mathrm{~F}$ & $71.5 \pm 11.8$ & $1-2$ & $7 \mathrm{E3} 0 \mathrm{E4}$ & & $7.7 \pm 4.7$ \\
\hline \multirow[t]{7}{*}{ Alzheimer's disease } & $\mathrm{F}$ & 59 & 5 & $4 / 4$ & EOAD & $4: 20$ \\
\hline & $\mathrm{F}$ & 66 & 5 & $4 / 3$ & EOAD & $6: 30$ \\
\hline & M & 70 & 4 & $4 / 4$ & EOAD & 4:00 \\
\hline & M & 78 & 5 & $4 / 4$ & LOAD & $6: 35$ \\
\hline & $\mathrm{F}$ & 81 & 5 & $4 / 3$ & LOAD & $6: 15$ \\
\hline & $\mathrm{F}$ & 85 & 4 & $3 / 3$ & LOAD & $6: 00$ \\
\hline & $2 M / 4 F$ & $73.1 \pm 9.8$ & $4-5$ & $1 \mathrm{E3} 5 \mathrm{E4}$ & 3EOAD/3LOAD & $5.5 \pm 1.0$ \\
\hline \multicolumn{7}{|c|}{ For large frozen section autoradiography studies } \\
\hline Control & $\mathrm{F}$ & 56 & N/A & N/A & N/A & N/A \\
\hline Sporadic Alzheimer's disease ${ }^{a}$ & $\mathrm{~F}$ & 79 & $\mathrm{~V}$ & $4 / 4$ & LOAD & $16: 00$ \\
\hline $\mathrm{A} \beta \mathrm{PPArc}^{\mathrm{a}}$ & M & 64 & VI & $3 / 3$ & EOAD & 12:00 \\
\hline
\end{tabular}

Bold values show the total number of male and female cases used in the study from control and AD cases as well as the means \pm standard deviation of age, Braak stage, ApoE allele forms, and postmortem delay time from these cases.

$A \beta P P A r c$ Arctic amyloid- $\beta$ protein precursor mutation, ApoE Apolipoprotein E, $M$ Male, $F$ Female, EOAD Early onset alzheimer's disease, $L O A D$ Late onset alzheimer's disease, N/A Not applicable/available.

${ }^{a}$ Sporadic Alzheimer's disease and AßPPArc cases have been also reported and described in our previous publications [39, 40, 70]. 
with reaction filters was counted on the next day with a beta scintillation counter (PerkinElmer Tri-Carb 2910TR). The saturation data was fitted and analysed using the non-linear regression function of GraphPad Prism 8.3 software [52] to calculate the dissociation constant $(\mathrm{Kd})$ and maximum number of binding sites (Bmax). Scatchard plots were prepared with GraphPad Prism 8.3 software to display the saturation binding data. For the $\mathrm{CN}$, the second binding site was drawn manually after fitting the data using the Hill slope-specific binding function in GraphPad Prism 8.3 software.

\section{Competition binding assays}

Competition binding assays for ${ }^{3} \mathrm{H}-\mathrm{BU} 99008$ and ${ }^{3} \mathrm{H}-$ Deprenyl were performed by using postmortem temporal cortex brain homogenate $(0.1 \mathrm{mg}$ tissue) from three $\mathrm{CNs}$ and two AD patients. The brain tissue homogenate was incubated with a single concentration of ${ }^{3} \mathrm{H}$-BU99008 $(1 \mathrm{nM})$ and ${ }^{3} \mathrm{H}$-Deprenyl $(10 \mathrm{nM})$ along with increasing concentrations of unlabelled BU99008 $\left(10^{-14}-10^{-5}\right)$, 2-BFI $\left(10^{-11}-10^{-5}\right)$, BU224 $\left(10^{-11}-10^{-5}\right)$ and Deprenyl $\left(10^{-14}\right.$ or $10^{-11}$ to $\left.10^{-5}\right)$ in binding buffer $(50 \mathrm{mM}$ Tris- $\mathrm{HCl}$ buffer, pH 7.4 for ${ }^{3} \mathrm{H}$-BU99008 and $50 \mathrm{mM}$ Na-K phosphate buffer, pH 7.4 for ${ }^{3} \mathrm{H}$-Deprenyl) for $1 \mathrm{~h}$ at $37^{\circ} \mathrm{C}$. After $1 \mathrm{~h}$ incubation a similar protocol as saturation binding assay was done and the binding was quantified using the scintillation counter.

${ }^{3} \mathrm{H}-\mathrm{BU} 99008$ competition binding assay with unlabelled BU99008 in the presence of reversible and irreversible MAO B inhibitors safinamide and deprenyl, respectively, was performed by using postmortem temporal cortex brain homogenate $(0.1 \mathrm{mg}$ tissue) from one $\mathrm{CN}$ and one $\mathrm{AD}$ patient. The brain tissue homogenate was incubated with a single concentration of ${ }^{3} \mathrm{H}-\mathrm{BU} 99008 \quad(1 \mathrm{nM})$ along with increasing concentrations of unlabelled BU99008 $\left(10^{-14}-10^{-4}\right)$, BU99008 and Deprenyl $\left(10^{-14}-10^{-4}\right)$ and BU99008 and safinamide $\left(10^{-14}-10^{-4}\right)$ in binding buffer (50 mM Tris- $\mathrm{HCl}$ buffer, $\mathrm{pH} 7.4$ ) for $1 \mathrm{~h}$ at $37^{\circ} \mathrm{C}$. A similar protocol as saturation binding assay was performed after $1 \mathrm{~h}$ incubation and the binding was quantified using the scintillation counter.

The competition binding data was fitted and analysed using non-linear regression competitive-binding function of GraphPad Prism 8.3 software [52] to determine IC50 (halfmaximal inhibitory concentration) values.

\section{${ }^{3} \mathrm{H}-\mathrm{BU} 99008$ brain regional binding studies}

Regional binding studies were performed on the frontal, parietal and temporal cortices, cerebellum and hippocampus brain homogenates $(0.1 \mathrm{mg}$ tissue) from six $\mathrm{CNs}$ and six $\mathrm{AD}$ patients. Brain homogenates from different brain regions were incubated with a single concentration of ${ }^{3} \mathrm{H}$ BU99008 $(1 \mathrm{nM})$ for $1 \mathrm{~h}$ at $37^{\circ} \mathrm{C}$ in $50 \mathrm{mM}$ Tris- HCI buffer, $\mathrm{pH}$ 7.4. After $1 \mathrm{~h}$ incubation, a similar protocol as saturation binding assay was done and the binding was quantified using the scintillation counter. Non-specific (NSP) binding was determined with $1 \mu \mathrm{M}$ unlabelled BU99008. Cerebellum tissue from one $\mathrm{CN}$, and frontal and hippocampal tissues from one $\mathrm{AD}$ case were not available. The binding data was analysed using GraphPad Prism 8.3 software [52] and presented in graphs as specific binding ( $\mathrm{fmol} / \mathrm{mg})$.

\section{In vitro autoradiography studies}

${ }^{3} \mathrm{H}$-BU99008 and ${ }^{3} \mathrm{H}$-Deprenyl autoradiography studies were performed on large frozen postmortem brain sections from one $\mathrm{CN}$, one patient with sporadic $\mathrm{AD}$ and one A PPPArc carrier case. The large frozen sections were allowed to dry at room temperature (RT) for 30-45 mins, followed by $1 \mathrm{~h}$ incubation with either ${ }^{3} \mathrm{H}$-BU99008 (1 $\mathrm{nM})$ or ${ }^{3} \mathrm{H}$-Deprenyl $(10 \mathrm{nM})$ at RT. Afterwards, the sections were rinsed for 5 mins three times in cold buffer (50 mM Tris-HCl buffer, pH 7.4 for ${ }^{3} \mathrm{H}-\mathrm{BU} 99008 ; 50$ $\mathrm{mM}$ Na-K phosphate buffer, $\mathrm{pH} 7.4$ for ${ }^{3} \mathrm{H}$-Deprenyl), followed by a quick dip in cold distilled water. The sections were allowed to dry at RT for $24 \mathrm{~h}$ and were then apposed together with a tritium standard (Larodan Fine Chemicals AB, Mälmo, Sweden) on a phosphorplate for 4 and 7 days for ${ }^{3} \mathrm{H}$-Deprenyl and ${ }^{3} \mathrm{H}$-BU99008, respectively, and then imaged using a BAS-2500 phosphor imager (Fujifilm, Tokyo, Japan). For semiquantitative analyses, the regions of interest (ROI) were drawn manually using multigauge software on the autoradiogram and the photostimulated luminescence per square millimeter (PSL/mm2) was transformed into fmol/mg using the standard curve to determine the total, NSP and specific binding of ${ }^{3} \mathrm{H}-\mathrm{BU} 99008$ and ${ }^{3} \mathrm{H}-$ Deprenyl in the ROI.

\section{Immunostaining on small paraffin sections}

GFAP immunostaining (astrocytes) was performed on small paraffin section from the right hemisphere of sporadic $A D$ brain using routine pathology method as described in our previous publication [39].

\section{Statistical analysis}

The difference in regional ${ }^{3} \mathrm{H}$-BU99008 binding between $\mathrm{CN}$ and $\mathrm{AD}$ cases was statistically examined using Two-way ANOVA (with Sidak's or Tukey's multiple comparisons test) analysis in GraphPad Prism 8.3 software. An ANOVA $p$ value $<0.05$ was considered 
significant. The data are presented as mean of three experiments performed in triplicate with a box and whiskers plot.

\section{Results}

\section{${ }^{3} \mathrm{H}$-BU99008 saturation binding studies in $\mathrm{CN}$ and AD brain tissue}

The ${ }^{3} \mathrm{H}-\mathrm{BU} 99008$ saturation binding study results and the saturation curves and Scatchard plots for the $\mathrm{CN}$ and $\mathrm{AD}$ brain tissue are illustrated in Fig. 1. For the $\mathrm{CN}$ tissue, saturation occurred at a $\mathrm{Kd}_{2}$ of $0.68 \mathrm{nM}$ and a $\mathrm{Bmax}_{2}$ of $58.8 \mathrm{fmol} / \mathrm{mg}$ (Fig. 1A). A second binding site (with a $\mathrm{Kd}_{1}$ of $0.03 \mathrm{nM}$ and a $B \max _{1}$ of $12 \mathrm{fmol} / \mathrm{mg}$ ) was also observed for the $\mathrm{CN}$ tissue when the Scatchard plot was manually drawn (Fig. 1A; blue dotted line). The saturation binding curve for the $\mathrm{AD}$ brain tissue showed two-binding sites with $\mathrm{Kd}_{1}$ and $\mathrm{Kd}_{2}$ values of 0.05 and $35.98 \mathrm{~nm}$ and $\mathrm{Bmax}_{1}$ and $\mathrm{Bmax}_{2}$ values of 19.53 and $316.2 \mathrm{fmol} / \mathrm{mg}$, respectively (Fig. 1B), indicating a 60-fold lower affinity and 5-fold higher Bmax for ${ }^{3} \mathrm{H}-\mathrm{BU} 99008$ in AD brain tissue than in $\mathrm{CN}$ tissue for the low-affinity site.

\section{${ }^{3} \mathrm{H}$-BU99008 competition binding studies with different unlabelled $\mathrm{I}_{2} \mathrm{BS}$ ligands in $\mathrm{CN}$ and $\mathrm{AD}$ brain tissue}

To further characterise ${ }^{3} \mathrm{H}$-BU99008 tracer binding properties, competition binding studies were performed with different concentrations of the unlabelled $\mathrm{I}_{2} \mathrm{BS}$ specific

A

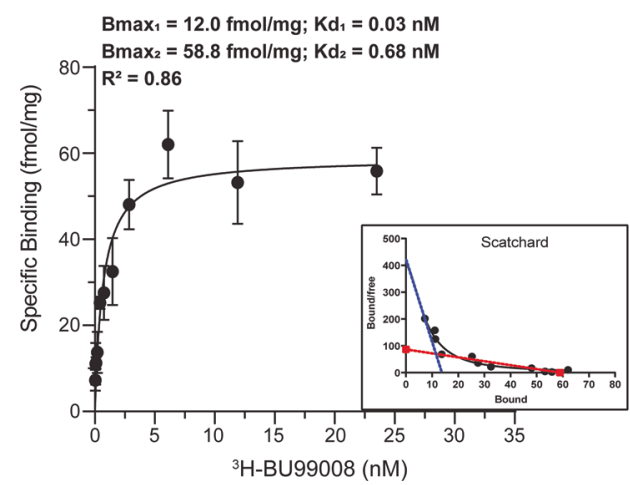

Fig. $1{ }^{3}$ H-BU99008 saturation binding assay. ${ }^{3} \mathrm{H}-\mathrm{BU} 99008$ saturation binding studies were performed in temporal cortex brain tissue homogenates from one $\mathrm{CN}$ and one patient with $\mathrm{AD}$ using increasing concentrations of ${ }^{3} \mathrm{H}$-BU99008 $(0-35 \mathrm{nM})$. A and B show the saturation binding curves for the $\mathrm{CN}$ (62 years) and Alzheimer's disease (85 years) cases, respectively, along with the corresponding ligands BU99008, 2-BFI and BU224. The results of the competition studies suggested a range of binding sites with different affinities for ${ }^{3} \mathrm{H}-\mathrm{BU} 99008$ as shown in Fig. 2. Unlabelled BU99008 and 2-BFI both showed two-binding sites for both $\mathrm{CN}$ and $\mathrm{AD}$ cases (Fig. 2A and B), whereas unlabelled BU224 also showed two-binding sites for the $\mathrm{CN}$ and a single binding site for the AD (Fig. 2C). For unlabelled BU99008 and 2-BFI, the IC50 1 values were $0.0003 \mathrm{nM}$ and $0.34 \mathrm{nM}$ for $\mathrm{CN}$ cases, respectively, and 1.43 and $0.041 \mathrm{nM}$ for $\mathrm{AD}$ cases, respectively, while the IC50 2 values were $2.45 \mathrm{nM}$ and $149.6 \mathrm{nM}$ for $\mathrm{CN}$ cases, respectively, and $342 \mathrm{nM}$ and $165 \mathrm{nM}$ for $\mathrm{AD}$ cases, respectively (Fig. 2A and B). In case of unlabelled BU224, the IC $50_{1}$ and IC $50_{2}$ values were $0.026 \mathrm{nM}$ and $186 \mathrm{nM}$ for the $\mathrm{CN}$ case, respectively, whereas the IC50 value for AD case was $416 \mathrm{nM}$ (Fig. 2C). We further analysed the data by calculating the proportion (\%) of different binding affinity sites for unlabelled BU99008, 2-BFI, and BU224 in $\mathrm{CN}$ and $\mathrm{AD}$ cases and grouped them into three groups (based on their IC50 values; Fig. 3): Super high-affinity (SH; $\left.10^{-13 \text { to }-11} \mathrm{M}\right)$, High-affinity (HA; $10^{-10 \text { to }-9} \mathrm{M}$ ) and Low-affinity (LA; $10^{-7}$ to ${ }^{-6} \mathrm{M}$ ) binding sites. The proportion of $\mathrm{SH}$ binding sites were $25 \%$ and $44 \%$ for BU99008 and BU224 in CN cases, respectively. Interestingly, BU99008 showed similar binding to HA binding sites for both $\mathrm{CN}$ and $\mathrm{AD}$ cases $(75 \%$ and $78 \%$, respectively) while a shift from SH binding sites (25\%) in CN to LA binding sites (22\%) in Alzheimer disease cases was observed. In CN, 2-BFI also showed a small percentage of HA binding sites (18\%) while a majority of the binding to LA sites (82\%). However, the LA binding sites remained the same in $\mathrm{AD}$ while the HA sites were shifted to $\mathrm{SH}$ binding sites (19\%). BU224 showed approximate similar

\section{B}

$$
\text { ( } 85 \text { years) }
$$

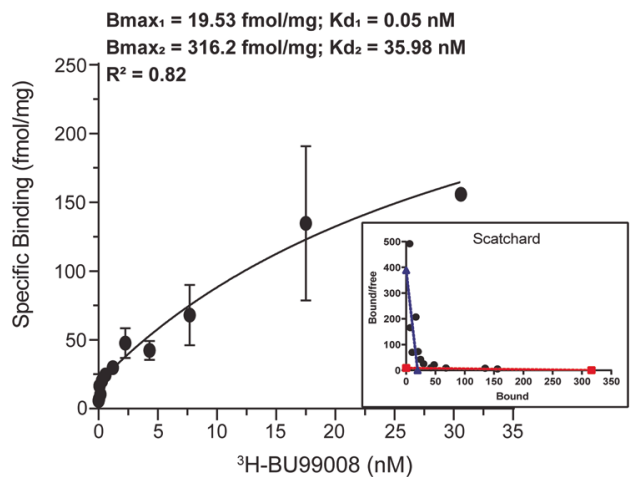

Scatchard plots. For the $\mathrm{CN}$, the second binding site was drawn manually after fitting the data using the Hill slope-specific binding function in GraphPad Prism 8.3 software (A; blue dotted line). Data are presented as means \pm SEM of two experiments in triplicate. $K d$ dissociation constant; Bmax- density of binding sites. 
A

${ }^{3} \mathrm{H}-\mathrm{BU} 99008$ vs. BU99008

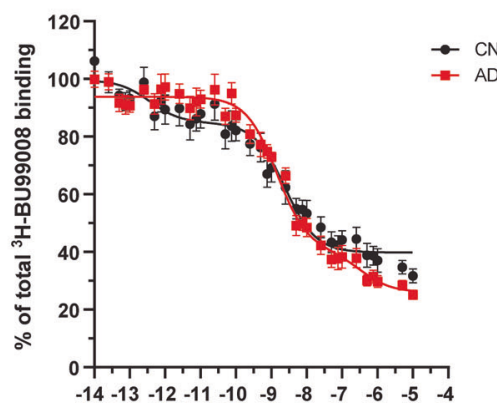

unlabelled compound $(\log C)$

$\mathrm{CN}-\mathrm{IC} 50_{1}=0.0003 \mathrm{nM} I C 50_{2}=2.45 \mathrm{nM}$ $\mathbf{R}^{2}=0.82$

$A D-I C 50_{1}=1.43 \mathrm{nM} I C 50_{2}=342 \mathrm{nM}$ $R^{2}=0.90$
B

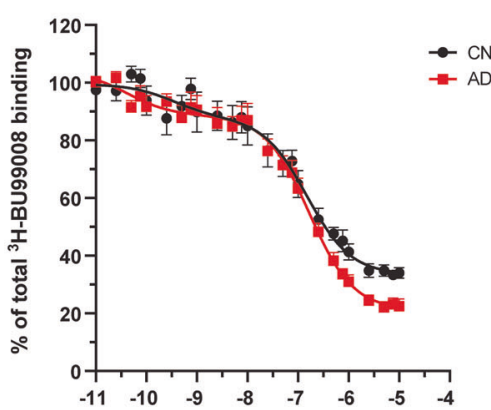

unlabelled compound $(\log C)$

$\mathrm{CN}-\mathrm{IC50}_{1}=0.34 \mathrm{nM} I \mathrm{IC50}=149.6 \mathrm{nM}$ $\mathrm{R}^{2}=0.85$

$A D-I C 50_{1}=0.041 \mathrm{nM} I C 50_{2}=165 \mathrm{nM}$ $R^{2}=0.92$
C

${ }^{3} \mathrm{H}-\mathrm{BU} 99008$ vs. BU224

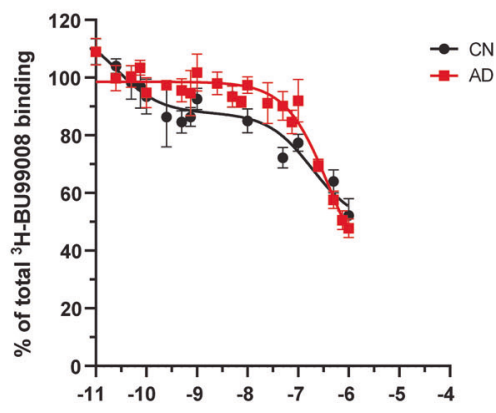

unlabelled compound $(\log C)$

$\mathrm{CN}-\mathrm{IC} 50_{1}=0.026 \mathrm{nM} \mathrm{IC} 50_{2}=186 \mathrm{nM}$

$\mathrm{R}^{2}=0.67$

$A D-I C 50=416 n M$

$R^{2}=0.73$

Fig. $2{ }^{3}$ H-BU99008 competition binding assay with different unlabelled $\mathbf{I}_{2} \mathbf{B S}$ ligands in $\mathbf{C N}$ and AD brain tissues. ${ }^{3} \mathrm{H}-\mathrm{BU} 99008$ competition binding studies were performed in temporal cortex brain homogenates from $\mathrm{CN}$ and $\mathrm{AD}$ brains using a single concentration of ${ }^{3} \mathrm{H}-\mathrm{BU} 99008(1 \mathrm{nM})$ and increasing concentrations of unlabelled $\mathrm{I}_{2} \mathrm{BS}$ ligands BU99008 (A), 2-BFI (B) and BU224 (C). Data are presented as

from two CNs (62 and 71 years) and two AD patients ( 78 and 85 years) for unlabelled BU99008 and 2-BFI, and one tissue sample from CN (50 years) and one $\mathrm{AD}$ patient (85 years) for unlabelled BU224. $2-B F I=2$ (benzofuran-2-yl)-2-imidazoline hydrochloride, BU224 $=2-(4,5-d i h y-$ droimidazol-2-yl) quinoline hydrochloride, $I_{2} B S=$ imidazoline-2 binding sites, IC50- half-maximal inhibitory concentration. means \pm SEM of 4-7 experiments in triplicate using two tissue samples

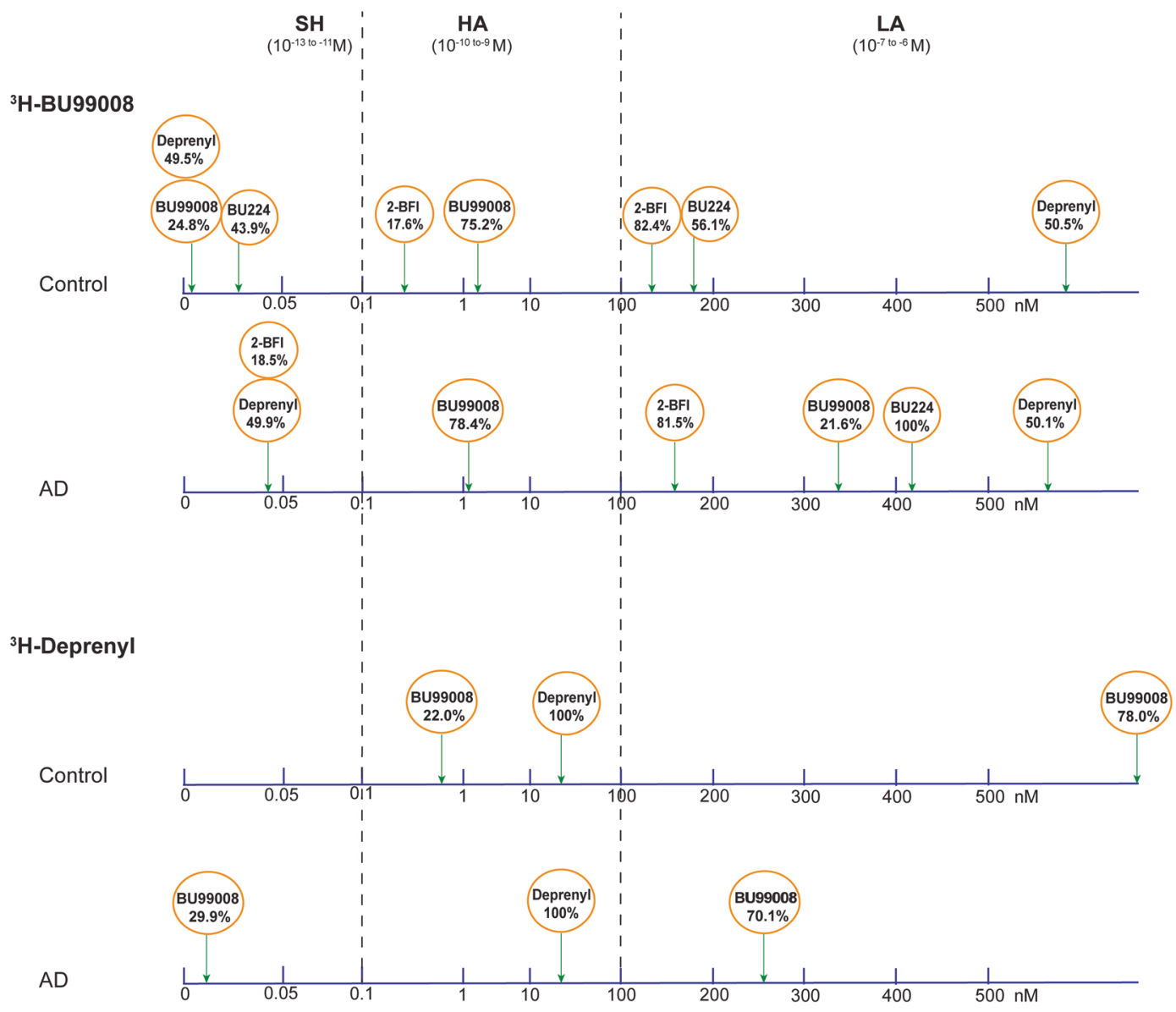

Fig. 3 Proportions (\%) of different binding sites for unlabelled BU99008, 2-BFI, BU-224 and deprenyl in postmortem CN and AD brain tissue revealed during ${ }^{3} \mathrm{H}-\mathrm{BU} \mathbf{9 9 0 0 8}$ and ${ }^{3} \mathrm{H}$-Deprenyl

competition studies. SH-Super high-affinity binding sites, HA- highaffinity binding sites, LA-low-affinity binding sites. 
proportion of binding to SH (44\%) and LA (56\%) sites in CNs which were all shifted to LA binding sites $(100 \%)$ in $\mathrm{AD}$ cases.

\section{${ }^{3} \mathrm{H}$-BU99008 and ${ }^{3} \mathrm{H}$-Deprenyl comparative competition binding studies in $\mathrm{CN}$ and $\mathrm{AD}$ brain tissue}

Next, we investigated the similarities/differences in the binding behaviour of ${ }^{3} \mathrm{H}$-BU99008 and ${ }^{3} \mathrm{H}$-Deprenyl with competition binding studies. We observed two-binding sites for unlabelled deprenyl vs. ${ }^{3} \mathrm{H}$-BU99008 while one-binding site vs. ${ }^{3} \mathrm{H}$-Deprenyl in both $\mathrm{CN}$ and $\mathrm{AD}$ cases, respectively (Fig. 4A and C). For unlabelled deprenyl and ${ }^{3} \mathrm{H}-\mathrm{BU} 99008$, the IC50 values were $0.0005 \mathrm{nM}$ and $1362 \mathrm{nM}$ for $\mathrm{CN}$ cases, respectively, and 0.012 and $938 \mathrm{nM}$ for $\mathrm{AD}$ cases, respectively, while the corresponding IC50 values for deprenyl vs. ${ }^{3} \mathrm{H}$-Deprenyl were $22.6 \mathrm{nM}$ for $\mathrm{CN}$ cases and $20.2 \mathrm{nM}$ for $\mathrm{AD}$ cases (Fig. 4A and C). There were two-binding sites for ${ }^{3} \mathrm{H}$-Deprenyl vs. unlabelled BU99008 in both CN (IC50 ${ }_{1}$ : $0.72 \mathrm{nM}, \mathrm{IC} \mathrm{O}_{2}: 3111 \mathrm{nM}$ ) and AD cases (IC50 $1: 0.002 \mathrm{nM}$, IC50 $2: 254 \mathrm{nM}$ ) (Fig. 4B). For ${ }^{3} \mathrm{H}-\mathrm{BU} 99008$, unlabelled deprenyl thus showed almost identical proportion of binding to $\mathrm{SH}(\sim 50 \%)$ and LA (50\%) binding sites in both $\mathrm{CN}$ and AD cases, respectively (Fig. 3). On the other hand, for ${ }^{3} \mathrm{H}-$ Deprenyl, unlabelled deprenyl showed $100 \%$ binding to HA site while unlabelled BU99008 demonstrated majority of binding to LA sites ( 70-78\%) in both $\mathrm{CN}$ and $\mathrm{AD}$ cases (Fig. 3).

\section{${ }^{3} \mathrm{H}$-BU99008 competition binding studies with unlabelled BU99008 in the presence of two MAO B inhibitors in CN and AD brain tissue}

To further investigate the specificity of ${ }^{3} \mathrm{H}-\mathrm{BU} 99008$ for the HA binding site competition studies were performed with unlabelled BU99008 alone and in the presence of safinamide (reversible MAO B inhibitors) or deprenyl (irreversible MAO B inhibitors). For CN, unlabelled BU99008 alone showed two-binding sites with almost comparable IC50 values of $0.0006 \mathrm{nM}(\mathrm{SH})$ and $2.81 \mathrm{nM}(\mathrm{HA})$ as shown in Fig. 2 competition studies (compare Fig. 2A and Fig. 5A). Interestingly, in the presence of MAO B inhibitors deprenyl or safinamide, the displacement curves shifted towards right and showed monophasic behaviour with only a single site fit with IC50 values in the HA range (Fig. 5A). The IC50 values were $1.85 \mathrm{nM}$ and $2.58 \mathrm{nM}$ in the presence of deprenyl and safinamide, respectively. In addition, we also observed a decrease of $\sim 15-30 \%$ in total binding in the lower concentration ranges $\left[10^{-14}-10^{-9}\right]$ in the presence of deprenyl or safinamide (Fig. 5A). Whereas in case of $\mathrm{AD}$ the unlabelled BU99008 alone and in the presence of MAO $\mathrm{B}$ inhibitors showed almost similar one-site binding curves with comparable IC50 values in the HA range (Fig. 5B). The IC50 values were $1.73 \mathrm{nM}, 1.90 \mathrm{nM}$ and $1.62 \mathrm{nM}$ for unlabelled BU99008 alone and in the presence of deprenyl and safinamide, respectively. Even though the curve for unlabelled BU99008 alone looked very similar as our competition studies (compare Fig. 2A and Fig. 5B), the LA
A

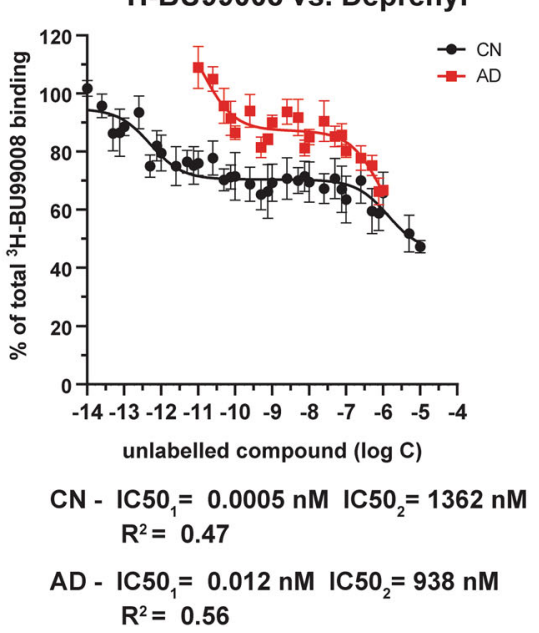

B

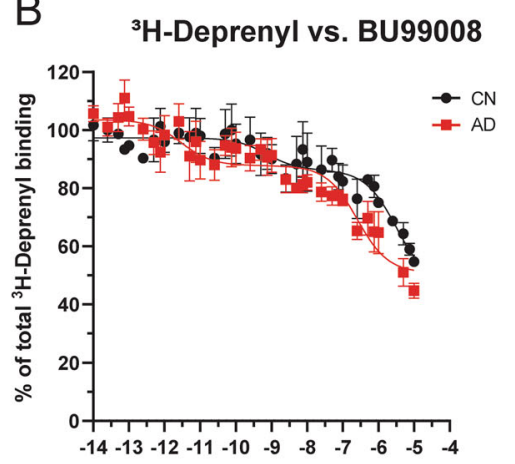

unlabelled compound $(\log C)$

$\mathrm{CN}-\mathrm{IC} 50_{1}=0.72 \mathrm{nM} I \mathrm{CC} 50_{2}=3111 \mathrm{nM}$ $R^{2}=0.62$

$A D-I C 50_{1}=0.002 \mathrm{nM} I C 50_{2}=254 \mathrm{nM}$ $R^{2}=0.74$
C

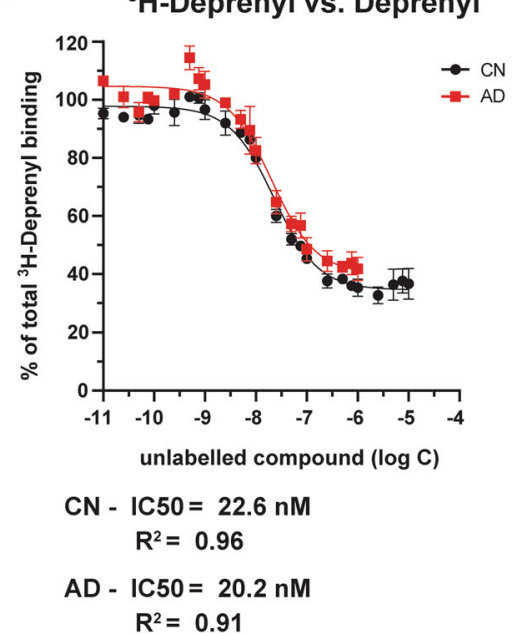

Fig. 4 Comparison of ${ }^{3} \mathrm{H}-\mathrm{BU} 99008$ and ${ }^{3} \mathrm{H}$-Deprenyl competition binding assay with unlabelled deprenyl and $\mathrm{BU} 99008$ in $\mathrm{CN}$ and AD brain tissue. ${ }^{3} \mathrm{H}$-BU 99008 and ${ }^{3} \mathrm{H}$-Deprenyl competition binding studies were performed in temporal cortex brain homogenates from one $\mathrm{CN}$ and one $\mathrm{AD}$ patient using a single concentration of ${ }^{3} \mathrm{H}$ BU99008 $(1 \mathrm{nM})$ and ${ }^{3} \mathrm{H}$-Deprenyl $(10 \mathrm{nM})$ against increasing concentrations of unlabelled deprenyl and BU99008: (A) ${ }^{3} \mathrm{H}-\mathrm{BU} 99008$ vs. deprenyl; B ${ }^{3} \mathrm{H}$-Deprenyl vs. BU99008; and $\mathbf{C}{ }^{3} \mathrm{H}$-Deprenyl vs. deprenyl. Data are presented as means \pm SEM of 3-4 experiments in triplicate using one tissue samples from $\mathrm{CN}$ (50 years for ${ }^{3} \mathrm{H}$ BU99008 vs. Deprenyl; 62 years for ${ }^{3} \mathrm{H}$-Deprenyl vs. BU99008 vs. Deprenyl) and AD (85 years) cases for unlabelled BU99008 and deprenyl, respectively. IC50- half-maximal inhibitory concentration. 
A

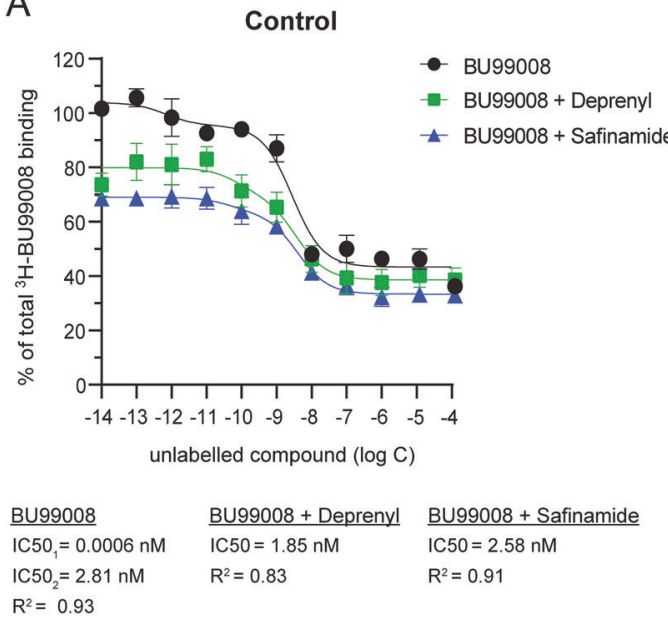

Fig. $5{ }^{3} \mathrm{H}$-BU99008 competition binding studies with unlabelled BU99008 in the presence of reversible and irreversible MAO B inhibitors. ${ }^{3} \mathrm{H}$-BU99008 competition binding studies with unlabelled BU99008 in the presence of MAO B inhibitors safinamide (reversible) or deprenyl (irreversible) were performed in temporal cortex brain homogenates from one $\mathrm{CN}(\mathbf{A} ; 71$ years $)$ and $\mathrm{AD}(\mathbf{B} ; 85$

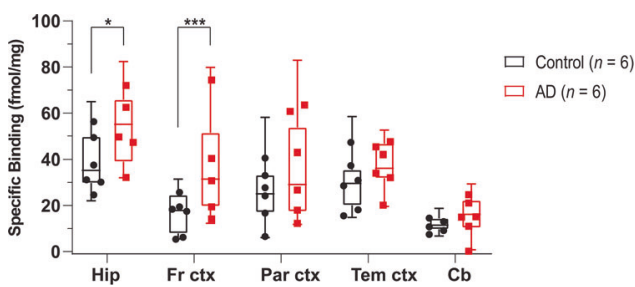

Fig. $6{ }^{3}$ H-BU99008 regional distribution binding studies in brain homogenates from CNs and patient with AD. ${ }^{3} \mathrm{H}-\mathrm{BU} 99008$ regional distribution binding studies in postmortem hippocampus, frontal cortex, parietal cortex, temporal cortex and cerebellum tissue from six CNs (mean age $75.1 \pm 7.6$ years) and six AD patients (mean age $73.1 \pm 9.8$ years) were performed using a single concentration of ${ }^{3} \mathrm{H}-$ BU99008 $(1 \mathrm{nM})$ and unlabelled BU99008 $(1 \mu \mathrm{M})$. The graph shows the comparison of ${ }^{3} \mathrm{H}$-BU99008 specific binding ( $\mathrm{fmol} / \mathrm{mg}$ ) in homogenates from different brain regions in $\mathrm{CN}$ and $\mathrm{AD}$ brains. Data are presented as box and whiskers plots with means of three experiments performed in triplicate for each case. $* p<0.05$, $* * * p=0.0002$. HipHippocampus, Fr ctx- Frontal cortex, Par ctx- Parietal cortex, Tem ctx- Temporal cortex, $\mathrm{Cb}$-Cerebellum.

binding site was undetectable in the analyses; this could be due to the smaller number of concentration points used in this experiment. Regardless of this, we also observed a pattern similar to that seen with the $\mathrm{CN}$ in the lower concentration ranges, with a decrease of $\sim 30-55 \%$ in total binding in the presence of MAO B inhibitors (Fig. 5B).

\section{${ }^{3} \mathrm{H}-\mathrm{BU} 99008$ regional distribution binding studies in $C N$ and $A D$ brain tissue homogenates}

${ }^{3} \mathrm{H}-\mathrm{BU} 99008$ (1 nM) regional distribution binding was assessed in five brain regions (frontal, parietal and temporal
B

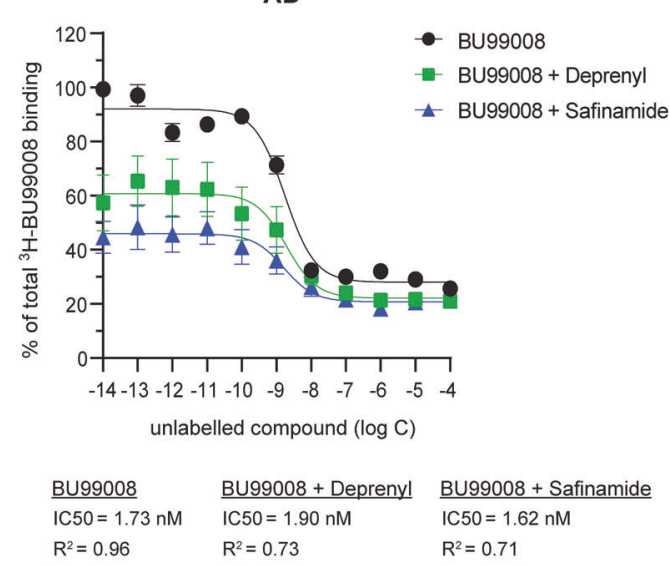

years) cases using a single concentration of ${ }^{3} \mathrm{H}-\mathrm{BU} 99008(1 \mathrm{nM})$ against increasing concentrations of unlabelled BU99008, BU99008 + Deprenyl or BU99008 + Safinamide, respectively. Data are presented as means \pm SEM of three experiments in triplicate. IC50- halfmaximal inhibitory concentration.

cortices, hippocampus and cerebellum) from six CNs (mean age $75.1 \pm 7.6$ years) and six patients with $\mathrm{AD}$ (mean age $73.1 \pm 9.8$ years). A significantly higher ${ }^{3} \mathrm{H}$-BU99008 binding was observed in the frontal cortex ( $p$ value $=$ $0.0002)$ and hippocampus ( $p$ value $<0.05$ ) of the AD brains as compared to $\mathrm{CN}$ brains (Fig. 6).

\section{${ }^{3} \mathrm{H}$-BU99008 and ${ }^{3} \mathrm{H}$-Deprenyl autoradiography regional binding studies in $\mathrm{CN}$ and sporadic $\mathrm{AD}$ brain sections}

${ }^{3} \mathrm{H}$-BU99008 and ${ }^{3} \mathrm{H}$-Deprenyl regional binding autoradiograms of large frozen sections from $\mathrm{CN}$ and $\mathrm{AD}$ brains are shown in Fig. 7. Visual assessment demonstrated similar regional distribution for ${ }^{3} \mathrm{H}$-BU99008 and ${ }^{3} \mathrm{H}$-Deprenyl in both the cases, with higher total binding in the sporadic $\mathrm{AD}$ brain as compared to $\mathrm{CN}$ brain (Fig. 7). ${ }^{3} \mathrm{H}-\mathrm{BU} 99008$ and ${ }^{3} \mathrm{H}$-Deprenyl both showed higher binding intensity in the temporal cortex and hippocampal regions as compared to CN brain (Fig. 7A-D). In addition, GFAP staining also demonstrated intense binding in the temporal cortical regions such as fusiform gyrus and inferior temporal gyrus of sporadic AD brain (Fig. 7B and D; Inset). We performed semiquantitative analyses to further assess ${ }^{3} \mathrm{H}$-BU99008 and ${ }^{3} \mathrm{H}$-Deprenyl regional binding differences and to calculate specific, NSP and total binding in the ROI such as frontal lobe, temporal lobe, insula and hippocampus. The semiquantitative analyses results for each case are presented in Fig. 7E. The specific binding of ${ }^{3} \mathrm{H}-\mathrm{BU} 99008$ in the cortical, subcortical and hippocampal regions of the sporadic AD brain was $~ 1.4-2.3$-fold higher as compared to the $\mathrm{CN}$ (Fig. 7E). For example, the specific binding of 


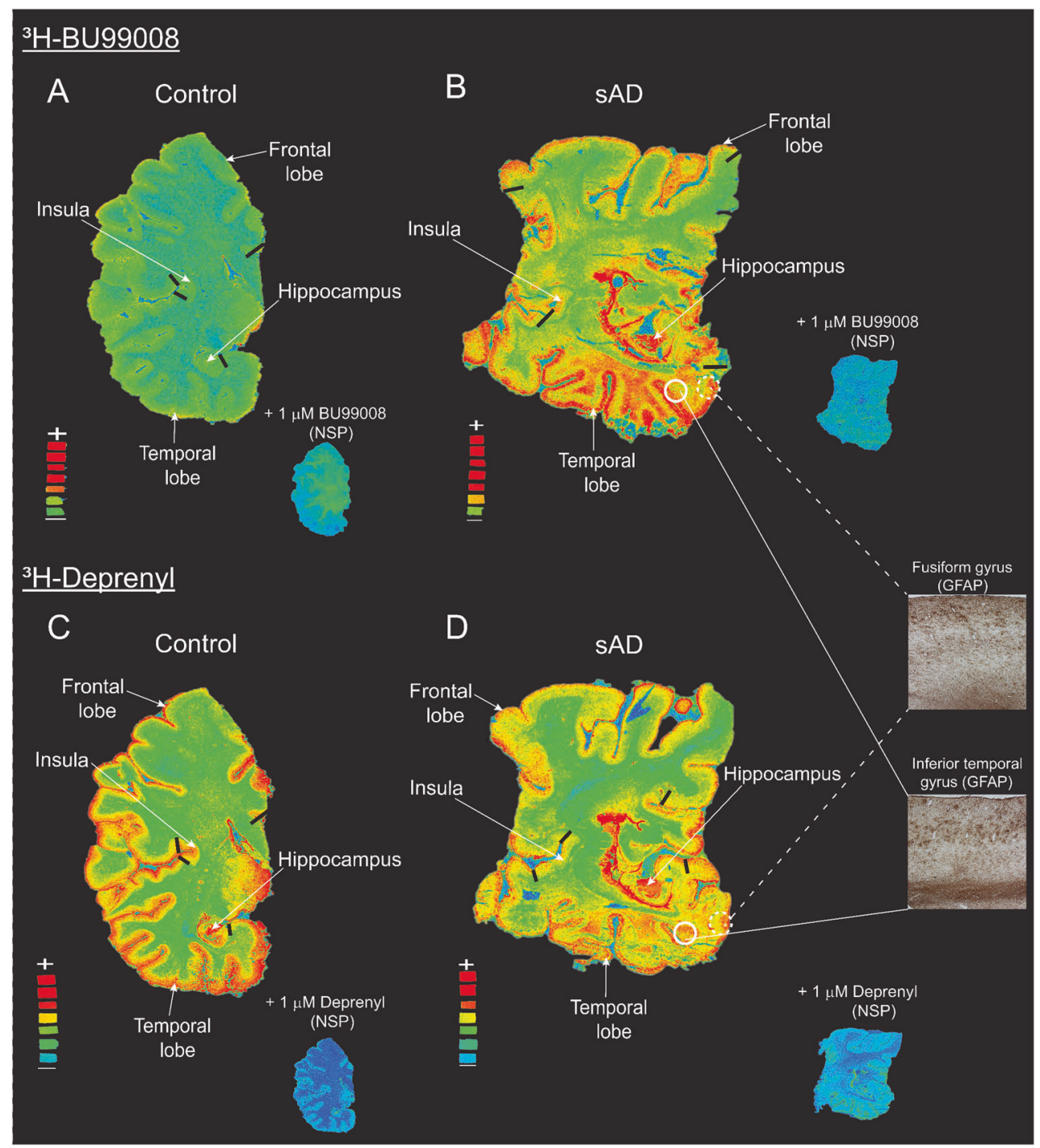

E

\begin{tabular}{|l|ccc|ccc|}
\hline${ }^{3}$ H-BU99008 regional binding (fmol/mg) \\
\hline $\begin{array}{l}\text { Region of } \\
\text { Interest }\end{array}$ & \multicolumn{3}{|c|}{ Control } & \multicolumn{3}{c|}{$\begin{array}{c}\text { Sporadic Alzheimer's } \\
\text { Disease }\end{array}$} \\
\hline & Specific & NSP & Total & Specific & NSP & Total \\
\hline Frontal lobe & 42 & 4 & 47 & 58 & 5 & 62 \\
Temporal lobe & 47 & 1 & 48 & 98 & 7 & 105 \\
Hippocampus & 39 & 4 & 43 & 91 & 8 & 99 \\
Insula & 22 & 16 & 38 & 39 & 7 & 46 \\
\hline${ }^{3}$ H-Deprenyl regional binding (fmol/mg) \\
\hline Frontal lobe & 399 & 19 & 418 & 589 & 53 & 642 \\
Temporal lobe & 502 & 24 & 526 & 731 & 80 & 811 \\
Hippocampus & 525 & 36 & 561 & 793 & 69 & 862 \\
Insula & 450 & 30 & 480 & 555 & 45 & 601 \\
\hline
\end{tabular}

${ }^{3} \mathrm{H}-\mathrm{BU} 99008$ in the hippocampal region of sporadic $\mathrm{AD}$ brain was $91 \mathrm{fmol} / \mathrm{mg}$ as compared to $39 \mathrm{fmol} / \mathrm{mg}$ in $\mathrm{CN}$ brain. For ${ }^{3} \mathrm{H}$-BU99008, co-incubation of sections with 1 $\mu \mathrm{M}$ unlabelled BU99008 showed $\sim 6-15 \%$ NSP binding in sporadic Alzheimer' disease brain ROI (7B and E), whereas in CN brain NSP binding was $2-9 \%$ in the ROI except in the subcortical region where NSP binding was $\sim 42 \%$
(Fig. 7A and E). In case of ${ }^{3} \mathrm{H}$-Deprenyl, the specific binding in the cortical, subcortical and hippocampal regions of sporadic AD brain was 1.2-1.5-fold higher as compared to the $\mathrm{CN}$ brain (Fig. 7E). Moreover, ${ }^{3} \mathrm{H}$-Deprenyl NSP after co-incubation of sections with $1 \mu \mathrm{M}$ unlabelled deprenyl was $\sim 4-6 \%$ and $\sim 7-10 \%$ of the total binding in these $\mathrm{ROI}$ in $\mathrm{CN}$ and sporadic $\mathrm{AD}$ brains, respectively 
Fig. $7{ }^{3} \mathrm{H}$-BU99008 and ${ }^{3} \mathrm{H}$-Deprenyl autoradiography comparative studies on large frozen postmortem brain sections from $\mathrm{CN}$ and sporadic Alzheimer's disease (sAD) cases. The figure shows the total binding of $1 \mathrm{nM}{ }^{3} \mathrm{H}$-BU99008 and $10 \mathrm{nM}{ }^{3} \mathrm{H}$-Deprenyl along with non-specific (NSP) binding in the presence of $1 \mu \mathrm{M}$ unlabelled BU99008 and Deprenyl in different brain regions of CN and SAD cases, respectively. For comparison, autoradiography images of ${ }^{3} \mathrm{H}$ BU99008 (Standards: $+=3407-3580 \mathrm{fmol} / \mathrm{mg},-=58 \mathrm{fmol} / \mathrm{mg}$ ) and ${ }^{3}$ H-Deprenyl (Standards: $+=3349-4740 \mathrm{fmol} / \mathrm{mg},-=54-77 \mathrm{fmol} /$ $\mathrm{mg}$ ) were set on the same color/brightness threshold levels of 44,461 $(\mathbf{A}, \mathbf{B})$ and $52,428(\mathbf{C}, \mathbf{D})$, respectively, from the raw images (16 bits: 0-65,535 (color scale)). B and D inset: GFAP immunostaining (astrocytes) in the temporal cortical regions of sAD case (40x magnification). E Regions of interest as shown in the figures were drawn manually to calculate the specific, non-specific and total binding values in fmol/mg. Frontal and temporal lobe regions were marked with dark black bars. ${ }^{3} \mathrm{H}$-Deprenyl autoradiography image for sAD case was adapted from [40]. Sporadic AD autoradiograms were rotated horizontally to be consistent (same orientation) with other images for comparison. NSP-Non-specific binding and GFAP-Glial fibrillary acidic protein.

(Fig. 7C, D and E). We also investigated the autoradiography regional binding differences between ${ }^{3} \mathrm{H}-\mathrm{BU} 99008$ and ${ }^{3} \mathrm{H}$-Deprenyl in the ABPParc mutation carrier brain sections (Supplementary Fig. 1). ${ }^{3} \mathrm{H}-\mathrm{BU} 99008$ showed relatively high total binding in the ROI of $A \beta P P$ arc mutation carrier brain section as compared to $\mathrm{CN}$ and sporadic AD brains (compare Fig. 7A, B and E with Supplementary Fig. 1A and $\mathrm{C}$ ). Whereas the total binding for ${ }^{3} \mathrm{H}$-Deprenyl in $\mathrm{CN}$ and ABPParc mutation carrier brains ROI were almost comparable except for the hippocampal region of the A $\beta P$ Parc mutation carrier brain where binding was $\sim 1.3$-fold higher (compare Fig. 7C, D and E with Supplementary Fig. 1B and C). In addition, ${ }^{3} \mathrm{H}$-Deprenyl also showed much higher NSP $(\sim 14-17 \%)$ as compared to ${ }^{3} \mathrm{H}-\mathrm{BU} 99008(\sim 2-8 \%)$ in the ABPParc mutation carrier brain section (Supplementary Fig. 1).

\section{Discussion}

The name 'Astrocytes' was coined by Micheal (Mihály) von Lenhossék in 1895 to represent a subtype of parenchymal glia cells [53]. Astrocytes are the main homeostatic cells in the CNS. They are highly heterogenous and can be further sub-classified into different types based on their regional distribution in the brain, for example, fibrous and velate astrocytes of the white matter and cerebellum, respectively [54]. They can undergo disease-specific modifications and complex neuropathological changes such as astrodegeneration (morphological atrophy and loss of function) and pathological remodelling (dysfunctional astroglia), that can further evolve with the disease progression, in addition to reactive astrogliosis [54]. As recent studies have put early reactive astrogliosis and glial- mediated neuroinflammation in the time course of $\mathrm{AD}$ pathogenesis, there is high interest in developing novel specific astrocytic-PET tracers to monitor the function of glial-neuronal network and to understand the time course of reactive astrogliosis during early-stages of disease progression. In this study, we reported for the first time the characterisation of ${ }^{3} \mathrm{H}-\mathrm{BU} 99008$ regional binding properties and its comparison with $\mathrm{I}_{2} \mathrm{BS}$ specific ligands (2-BFI and BU224) and deprenyl using radioligand binding studies in postmortem $\mathrm{AD}$ and $\mathrm{CN}$ brain tissues. We have also presented results of a head-to-head in vitro autoradiography comparison of ${ }^{3} \mathrm{H}$-BU99008 and ${ }^{3} \mathrm{H}$-Deprenyl binding behaviour in $\mathrm{CN}$, sporadic $\mathrm{AD}$ and ABPParc mutation carrier cases using large frozen human brain sections to further evaluate the potential of BU99008 as a novel astrocytic-PET tracer for $\mathrm{AD}$ and other dementia disorders.

Our saturation binding studies demonstrated the presence of two-binding sites with high-and low-affinity for ${ }^{3} \mathrm{H}$ BU99008 in both CN and AD temporal cortex brain tissue homogenates with a 60-fold lower binding affinity and 5fold higher Bmax for the major low-affinity site of ${ }^{3} \mathrm{H}$ BU99008 in AD compared to $\mathrm{CN}$ tissue $(\mathrm{Bmax}=316.2$ $\mathrm{fmol} / \mathrm{mg}$ compared to $\mathrm{Bmax}=58.8 \mathrm{fmol} / \mathrm{mg}$, respectively). This observation is in agreement with previous findings using ${ }^{3} \mathrm{H}$-idazoxan that showed upregulation in the density of $\mathrm{I}_{2} \mathrm{BS}$ in postmortem $\mathrm{AD}$ brain tissue samples [50] and appears to suggest that the low-affinity BU99008 site corresponds to the $\mathrm{I}_{2} \mathrm{BS}$. The difference in ${ }^{3} \mathrm{H}$-BU99008 binding affinities between the $\mathrm{CN}$ and $\mathrm{AD}$ brain tissue could be attributed to the substantial heterogeneity and complex changes in the subtypes of astrocytes in AD pathology. It is well documented that physiological and morphological properties of astrocytes can vary from region to region or within the same region in the brain and that they can respond differently via a range of activation states at both cellular and molecular levels in normal and diseased cases $[12,17,55-58]$. We also observed based on our in vivo ${ }^{11} \mathrm{C}$-DED PET studies from presymptomatic to symptomatic stages of $\mathrm{AD}[27,29,36,37]$ and in vitro postmortem brain studies at end stage of the disease [59] (see also Ni et al.; $J A D$; manuscript in press) suggest that there are dynamic changes in DED binding in AD; increased DED binding at presymptomatic/prodromal stages, lower DED binding (at $\mathrm{AD}$ dementia) and then at late stage of dementia (postmortem) increase again in DED binding which most probably reflect different stage of the astrocytes as well as different forms of astrocytes (e.g. A1, A2) [12]. It is probable that similar dynamic changes in BU99008 binding could also observed at different stages of $\mathrm{AD}$, however, these observations need further research and explorations. Moreover, a completely new population of astrocytes, defined as disease-associated astrocytes (DAAs) has recently been identified in the AD mouse model by Habib 
et al. They showed that DAAs are unique to $\mathrm{AD}$ and appear during the early stages while also becoming more abundant as the disease progresses [60]. Based on all these reports and speculations, it is highly likely that ${ }^{3} \mathrm{H}$-BU99008 could be targeting a completely diverse population of astrocytes in $\mathrm{CN}$ and $\mathrm{AD}$ brains hence displaying different binding affinities.

${ }^{3} \mathrm{H}$-BU99008 competition studies with different unlabelled $\mathrm{I}_{2} \mathrm{BS}$ specific ligands such as BU99008, 2-BFI and BU224 as well as with MAO inhibitor deprenyl revealed multiple binding sites with a wide range of binding affinities in both $\mathrm{CN}$ and $\mathrm{AD}$ temporal cortex brain tissue homogenates. We categorised these binding sites into three groups (based on their IC50 values; Fig. 3): Super highaffinity (SH), High-affinity (HA) and Low-affinity (LA) binding sites. The proportions (\%) of these sites varied significantly between compounds as well as between $\mathrm{CN}$ and AD cases with BU99008 explicitly showing a majority of binding ( 75-78\%) to HA binding sites in both cases. On the contrary, similar competition studies of ${ }^{3} \mathrm{H}$-Deprenyl with unlabelled BU99008 and deprenyl demonstrated completely opposing binding behaviour for both compounds, with BU99008 exhibiting the majority of binding $(\sim 70-78 \%)$ to LA binding sites and deprenyl to HA binding sites (100\%; one-site fit with IC50 value of $\sim 20 \mathrm{nM}$ ) in both $\mathrm{CN}$ and AD cases, highlighting differences in ${ }^{3} \mathrm{H}-\mathrm{BU} 99008$ and ${ }^{3} \mathrm{H}$-Deprenyl binding behaviour. A recent study with the novel MAO B PET tracer ${ }^{18} \mathrm{~F}$-SMBT also demonstrated a single binding site with a $\mathrm{Kd}$ value of $3.5 \mathrm{nM}$ in $\mathrm{AD}$ brain homogenate [61], which further complement our findings that MAO B ligands can only target/detect one-site in $\mathrm{AD}$ brains.

An important aspect to consider while interpreting in vitro binding results is that MAO B co-expresses with $\mathrm{I}_{2} \mathrm{BS}$ and also possesses a distinct $\mathrm{I}_{2} \mathrm{~B}$ site that is situated away from the active/substrate site [62, 63] and thereby possibility of ${ }^{3} \mathrm{H}$-BU99008 off-target binding to MAO B is very likely. However, recently published in vivo blocking studies with $\mathrm{MAO} \mathrm{B}$ and $\mathrm{I}_{2} \mathrm{BS}$ inhibitors in rhesus monkeys and healthy CNs demonstrated a high selectivity and specificity of radiolabeled BU99008 for astrocytic $\mathrm{I}_{2} \mathrm{BS}$ $[43,51]$. Both studies showed that the brain uptake of ${ }^{11} \mathrm{C}$ BU99008 was not affected by blocking with MAO B inhibitors whereas pretreatment with selective $\mathrm{I}_{2} \mathrm{BS}$ inhibitor BU224 significantly reduced the ${ }^{11} \mathrm{C}$-BU99008 signal throughout the rhesus brain in a dose-dependent manner. In case of human brain, pretreatment with the mixed $\mathrm{I}_{2} \mathrm{BS} / \alpha 2$ adrenoceptor inhibitor idazoxan also reduced ${ }^{11} \mathrm{C}$-BU99008 uptake throughout the brain with an average block of $60 \%$ across all regions at the highest dose of $80 \mathrm{mg}$. As the blockade was not dose-dependent, authors suggested that this could be due to biphasic blockade by idazoxan. We also demonstrated similar properties for ${ }^{3} \mathrm{H}-\mathrm{BU} 99008$ using competition studies, where binding of BU99008 to HA binding sites in both $\mathrm{CN}$ and $\mathrm{AD}$ cases was not affected by the increasing concentrations of MAO B inhibitors deprenyl and safinamide. However, binding of BU99008 to the SH binding sites in $\mathrm{CN}$ was completely blocked in the presence of deprenyl or safinamide along with a decrease in ${ }^{3} \mathrm{H}-$ BU99008 total binding suggesting two possibilities: First, that the SH binding site might represent the MAO B binding site. Second, that MAO B inhibitors might interact with BU99008 and subsequently interfere with BU99008 binding, with the extent of interference depending on the mode of binding of these inhibitors on MAO B (see Edmondson et al., 2009, for details regarding MAO B inhibitors binding mechanisms). These observations are an incentive to perform further explorative mechanistic and structural based studies.

In this study, we also compared the regional distribution of ${ }^{3} \mathrm{H}$-BU99008 binding in $\mathrm{CN}$ and $\mathrm{AD}$ brain tissue homogenates and demonstrated significantly more extensive ${ }^{3} \mathrm{H}-\mathrm{BU} 99008$ binding in the frontal cortex $(p=0.0002)$ and hippocampus $(p<0.05)$ of the AD brains as compared to $\mathrm{CN}$ brains. We observed lowest binding for ${ }^{3} \mathrm{H}-\mathrm{BU} 99008$ in the cerebellum which was expected based on the recently published ${ }^{11} \mathrm{C}$-BU99008 human in vivo studies where tracer uptake in cerebellum was also low [43]. Even though we also observed differences in ${ }^{3} \mathrm{H}$-BU99008 binding between $\mathrm{CN}$ and $\mathrm{AD}$ brains in the temporal cortex, they were not as significant as observed in our saturation studies. One of the reasons could be the differences in the experimental setup, as regional binding studies were normally performed with a single concentration of ${ }^{3} \mathrm{H}$-BU99008 $(1 \mathrm{nM})$, whereas a much wider concentration range was used in saturation binding studies $(0-35 \mathrm{nM})$. The possibility of detecting all the binding sites (with high-, intermediate- and low-affinity) is much higher with a broader concentration range. Moreover, regional binding studies were performed on a larger number of cases $(n=6)$ whereas only one case was used for the saturation binding studies. This also points towards possible case-by-case variability and reintroduce the concept of astrocyte heterogeneity back into the picture as discussed above. Regardless of this, our findings are in agreement with earlier postmortem AD brain tissue studies, where increased reactive astrogliosis was observed in the cortical and hippocampal regions of brains with high amyloid- $\beta$ or tau burdens $[20,39,64,65]$.

Autoradiography comparative studies suggested similar regional binding patterns for both ${ }^{3} \mathrm{H}-\mathrm{BU} 99008$ and ${ }^{3} \mathrm{H}$-Deprenyl in sporadic AD, ABPParc mutation carrier and $\mathrm{CN}$ brains. However, a difference was observed in the numeric binding intensity of the two tracers which could be either due to different concentrations of tracer used for the experiments $\left(10 \mathrm{nM}\right.$ for ${ }^{3} \mathrm{H}$-Deprenyl vs. $1 \mathrm{nM}$ for ${ }^{3} \mathrm{H}$-BU99008) or higher NSP binding in case of 
${ }^{3} \mathrm{H}$-Deprenyl. The binding distribution of ${ }^{3} \mathrm{H}$-BU99008 followed the rank order: hippocampus and cortex $>$ subcortical regions. This observation was in line with our ${ }^{3} \mathrm{H}-$ BU99008 brain homogenate regional binding findings and previous human brain autoradiography studies showing the highest $\mathrm{I}_{2} \mathrm{BS}$ densities in hippocampal regions (dentate gyrus) and more moderate densities in cortical regions [66, 67]. In addition, the ${ }^{3} \mathrm{H}-\mathrm{BU} 99008$ binding distribution correlated very well with the increased GFAP immunoreactive levels in the temporal cortical areas. It is important to mention here that in vivo ${ }^{11} \mathrm{C}$-BU99008 human PETstudies also highlighted some off-target bindings in striatum and other subcortical areas with low $\mathrm{I}_{2} \mathrm{Bs}$ density [43]. However, this need to be further confirmed in large sample size as they suggested that higher binding in these areas should be carefully interpreted due to large test-retest variability. We also observed a higher binding for ${ }^{3} \mathrm{H}-$ BU99008 in the ABPParc mutation carrier brains as compared to sporadic $\mathrm{AD}$ brains this could be due to pathological differences between the two cases as the ABPParc mutation has been shown to promote the formation of amyloid- $\beta$ oligomers and protofibrils [68]. On the other hand, the binding for ${ }^{3} \mathrm{H}$-Deprenyl was comparable between the $\mathrm{CN}$ and the ABPParc mutation carrier brains. These observations further highlight possible differences in binding properties between ${ }^{3} \mathrm{H}$-BU99008 and ${ }^{3} \mathrm{H}$-Deprenyl (as also observed in our competition studies) and indicate that their targets are most likely somewhat different. It is possible that ${ }^{3} \mathrm{H}$-BU99008 and ${ }^{3} \mathrm{H}$-Deprenyl are targeting a different subtype of reactive astrocyte or a specific reactive state, not all reactive astrocytes. However, it is very important to keep the fact in mind that large frozen hemisphere sections are rare material and the sections used in this study did not originate from exactly the same coronal anatomical level; therefore the results of direct comparison between the cases should be interpreted cautiously. To summarise, our findings suggest that ${ }^{3} \mathrm{H}-\mathrm{BU} 99008$ could detect $\mathrm{I}_{2} \mathrm{BS}$ expressing reactive astrocytes with good selectivity and specificity, as also recently demonstrated by an in vivo ${ }^{11} \mathrm{C}$-BU99008 PET-study in Parkinson's disease patients [69]. However, one limitation of this study is that the binding studies were performed on a small number of brains and it would be interesting to further explore the ${ }^{3} \mathrm{H}-$ BU99008 binding characteristics in larger sample sizes.

Overall, this study reports, for the first time, the presence of multiple binding sites (SH, HA and LA) for ${ }^{3} \mathrm{H}-$ BU99008, $\mathrm{I}_{2} \mathrm{BS}$-specific ligands and deprenyl in $\mathrm{CN}$ and AD brains and demonstrate that ${ }^{3} \mathrm{H}-\mathrm{BU} 99008$ could possibly detect/target reactive astrogliosis in $\mathrm{AD}$ brains. Based on our competition and regional binding studies and upon comparison with the MAO-B inhibitor deprenyl, we conclude that ${ }^{3} \mathrm{H}$-BU99008 binds specifically to HA binding sites and its binding behaviour and properties appear to be different from those of ${ }^{3} \mathrm{H}$-Deprenyl in $\mathrm{CN}$, and sporadic AD brains. Even though studies have established reactive astrogliosis as one of the hallmarks of the AD brains, their role in the pathogenesis of the disease is still a topic of debate. Further in vivo and in vitro studies in large numbers of $\mathrm{CN}$ and sporadic and autosomal dominant $\mathrm{AD}$ cases are needed to establish the reliability of BU99008 as a specific PET-tracer and $\mathrm{I}_{2} \mathrm{BS}$ as a surrogate marker for reactive astrogliosis. This will contribute to a better understanding of the time course and pathophysiological role of reactive astrogliosis in $\mathrm{AD}$.

\section{Data availability}

All the data supporting the findings of this study are presented in the paper. Raw data for this study may be available from the corresponding author upon reasonable request.

Acknowledgements We would like to thank the Brain Bank at Karolinska Institutet for providing AD brain tissue. We would like to thank the Netherlands Brain Bank for providing the $\mathrm{CN}$ and $\mathrm{AD}$ human brains used in the in vitro homogenate binding assays. We would also like to thank Mrs Rose Marie Richardson, Department of Pathology and Laboratory Medicine, Indiana University School of Medicine, Indianapolis, USA, for the preparation and shipment of tissue specimens. This study was financially supported by the Swedish Foundation for Strategic Research (SSF) (RB13-0192), the Swedish Research Council (2017-02965, 2017-06086), the Stockholm Region-Karolinska Institutet regional agreement on medical training and clinical research (ALF grant), the Swedish Brain Foundation, the Swedish Alzheimer Foundation, Foundation for Old Servants, Gun and Bertil Stohne's Foundation, Loo and Hans Osterman's Foundation, the Tore Nilsson Foundation, the KI Foundation for Geriatric Diseases, the Swedish dementia foundation, and the Center for Innovative Medicine (CIMED) Karolinska Institutet, Stockholm Region. BG received funding from Public Health Service (PHS; P30 AG010133).

Author contributions AN conceptualised the project. AK, LL and AN designed the study. NK performed the saturation binding assays. AK and NK performed the competition binding assays. AK and MLM performed regional distribution experiments. AK, MLM and LL performed autoradiography experiments. AK and LL analysed the autoradiography data and drew the regions of interest. IN performed the GFAP immunostaining. AK, LL and AN analysed all the data. AK wrote the first draft of the paper. All the authors have provided critical input and feedback during writing of the paper. All authors read and approved the final version of the paper.

\section{Compliance with ethical standards}

Conflict of interest The authors declare no competing interests.

Ethical approval All experiments on autopsied human brain tissue were carried out in accordance with ethical permission obtained from the regional human ethics committee in Stockholm (permission number 2011/962/31-1; 2006/901-31/3 and 2017/2301-32), Uppsala (2005/ 103, 2011/044), the medical ethics committee of 
the VU Medical Center for the Netherlands Brain Bank tissue (permission number 1998-06/5), and Indiana University Institutional Review Board.

Informed consent Informed consent was obtained for all cases investigated.

Publisher's note Springer Nature remains neutral with regard to jurisdictional claims in published maps and institutional affiliations.

Open Access This article is licensed under a Creative Commons Attribution 4.0 International License, which permits use, sharing, adaptation, distribution and reproduction in any medium or format, as long as you give appropriate credit to the original author(s) and the source, provide a link to the Creative Commons license, and indicate if changes were made. The images or other third party material in this article are included in the article's Creative Commons license, unless indicated otherwise in a credit line to the material. If material is not included in the article's Creative Commons license and your intended use is not permitted by statutory regulation or exceeds the permitted use, you will need to obtain permission directly from the copyright holder. To view a copy of this license, visit http://creativecommons. org/licenses/by/4.0/.

\section{References}

1. Jäkel S, Dimou L. Glial Cells and Their Function in the Adult Brain: a Journey through the History of Their Ablation. Front Cell Neurosci. 2017;11:24.

2. Fakhoury M. Microglia and Astrocytes in Alzheimer's Disease: implications for Therapy. Curr Neuropharmacol. 2018;16:508-18.

3. Vasile F, Dossi E, Rouach N. Human astrocytes: structure and functions in the healthy brain. Brain Struct Funct. 2017;222:2017-29.

4. Verkhratsky A, Nedergaard M. Physiology of Astroglia. Physiological Rev. 2018;98:239-389.

5. Verkhratsky A, Butt AM. The History of the Decline and Fall of the Glial Numbers Legend. Neuroglia. 2018;1:188-92.

6. Azevedo FAC, Carvalho LRB, Grinberg LT, Farfel JM, Ferretti REL, Leite REP, et al. Equal numbers of neuronal and nonneuronal cells make the human brain an isometrically scaled-up primate brain. J Comp Neurol. 2009;513:532-41.

7. Carter SF, Herholz K, Rosa-Neto P, Pellerin L, Nordberg A, Zimmer ER. Astrocyte Biomarkers in Alzheimer's Disease. Trends Mol Med. 2019;25:77-95.

8. Danbolt NC, Furness DN, Zhou Y. Neuronal vs glial glutamate uptake: resolving the conundrum. Neurochemistry Int. 2016;98:29-45.

9. Adamsky A, Kol A, Kreisel T, Doron A, Ozeri-Engelhard N, Melcer T, et al. Astrocytic Activation Generates De Novo Neuronal Potentiation and Memory Enhancement. Cell. 2018;174:59-71. e14

10. Kol A, Adamsky A, Groysman M, Kreisel T, London M, Goshen I. Astrocytes contribute to remote memory formation by modulating hippocampal-cortical communication during learning. Nat Neurosci. 2020;23:1229-39.

11. Pekny M, Pekna M. Reactive gliosis in the pathogenesis of CNS diseases. Biochimica et Biophysica Acta (BBA) - Mol Basis Dis. 2016;1862:483-91.

12. Liddelow SA, Barres BA. Reactive Astrocytes: production, Function, and Therapeutic Potential. Immunity. 2017;46:957-67.
13. Escartin C, Galea E, Lakatos A, O'Callaghan JP, Petzold GC, Serrano-Pozo A, et al. Reactive astrocyte nomenclature, definitions, and future directions. Nat Neurosci. 2021;24:312-25.

14. Radford RA, Morsch M, Rayner SL, Cole NJ, Pountney DL, Chung RS. The established and emerging roles of astrocytes and microglia in amyotrophic lateral sclerosis and frontotemporal dementia. Front Cell Neurosci. 2015;9:414.

15. Nordberg A. Molecular imaging in Alzheimer's disease: new perspectives on biomarkers for early diagnosis and drug development. Alzheimer's Res Ther. 2011;3:34.

16. Heneka MT, Carson MJ, El Khoury J, Landreth GE, Brosseron F, Feinstein DL, et al. Neuroinflammation in Alzheimer's disease. Lancet Neurol. 2015;14:388-405.

17. Liddelow SA, Guttenplan KA, Clarke LE, Bennett FC, Bohlen CJ, Schirmer L, et al. Neurotoxic reactive astrocytes are induced by activated microglia. Nature. 2017;541:481-7.

18. Wisniewski HM, Wegiel J. Spatial relationships between astrocytes and classical plaque components. Neurobiol Aging. 1991;12:593-600.

19. Beach TG, Walker R, McGeer EG. Patterns of gliosis in Alzheimer's disease and aging cerebrum. Glia. 1989;2:420-36.

20. Yu WF, Guan ZZ, Bogdanovic N, Nordberg A. High selective expression of alpha7 nicotinic receptors on astrocytes in the brains of patients with sporadic Alzheimer's disease and patients carrying Swedish APP 670/671 mutation: a possible association with neuritic plaques. Exp Neurol. 2005;192:215-25.

21. Kadir A, Marutle A, Gonzalez D, Schöll M, Almkvist O, Mousavi $\mathrm{M}$, et al. Positron emission tomography imaging and clinical progression in relation to molecular pathology in the first Pittsburgh Compound B positron emission tomography patient with Alzheimer's disease. Brain. 2011;134:301-17.

22. Sajja VS, Hlavac N, VandeVord PJ. Role of Glia in Memory Deficits Following Traumatic Brain Injury: biomarkers of Glia Dysfunction. Frontiers in Integrative. Neuroscience. 2016;10:7.

23. Heneka MT, Rodríguez JJ, Verkhratsky A. Neuroglia in neurodegeneration. Brain Res Rev. 2010;63:189-211.

24. Orre M, Kamphuis W, Osborn LM, Jansen AHP, Kooijman L, Bossers K, et al. Isolation of glia from Alzheimer's mice reveals inflammation and dysfunction. Neurobiol Aging. 2014;35:2746-60.

25. Broe M, Kril J, Halliday GM. Astrocytic degeneration relates to the severity of disease in frontotemporal dementia. Brain 2004;127:2214-20. Pt 10

26. Verkhratsky A, Olabarria M, Noristani HN, Yeh CY, Rodriguez JJ. Astrocytes in Alzheimer's disease. Neurotherapeutics 2010;7:399-412.

27. Carter SF, Scholl M, Almkvist O, Wall A, Engler H, Langstrom B, et al. Evidence for astrocytosis in prodromal Alzheimer disease provided by $11 \mathrm{C}$-deuterium-L-deprenyl: a multitracer PET paradigm combining 11C-Pittsburgh compound B and 18F-FDG. J Nucl Med. 2012;53:37-46.

28. Nordberg A. Molecular imaging in sporadic Alzheimer's disease populations and those genetically at risk. Neurodegenerative Dis. 2014;13:160-2.

29. Rodriguez-Vieitez E, Ni R, Gulyas B, Toth M, Haggkvist J, Halldin $\mathrm{C}$, et al. Astrocytosis precedes amyloid plaque deposition in Alzheimer APPswe transgenic mouse brain: a correlative positron emission tomography and in vitro imaging study. Eur $\mathrm{J}$ Nucl Med Mol Imaging. 2015;42:1119-32.

30. Jossan SS, d'Argy R, Gillberg PG, Aquilonius SM, Långström B, Halldin C, et al. Localization of monoamine oxidase B in human brain by autoradiographical use of 11C-labelled L-deprenyl. J Neural Transm. 1989;77:55-64.

31. Jossan SS, Gillberg PG, Gottfries CG, Karlsson I, Oreland L. Monoamine oxidase B in brains from patients with Alzheimer's 
disease: a biochemical and autoradiographical study. Neuroscience. 1991;45:1-12.

32. Bergström M, Kumlien E, Lilja A, Tyrefors N, Westerberg G, Langstrom B. Temporal lobe epilepsy visualized with PET with C-11-L-deuterium-deprenyl - analysis of kinetic data. Acta Neurologica Scandinavica. 1998;98:224-31.

33. Kumlien E, Nilsson A, Hagberg G, Langstrom B, Bergstrom M. PET with 11C-deuterium-deprenyl and 18F-FDG in focal epilepsy. Acta Neurologica Scandinavica. 2001;103:360-6.

34. Engler H, Lundberg PO, Ekbom K, Nennesmo I, Nilsson A, Bergstrom $\mathrm{M}$, et al. Multitracer study with positron emission tomography in Creutzfeldt-Jakob disease. Eur J Nucl Med Mol Imaging. 2003;30:85-95.

35. Johansson A, Engler H, Blomquist G, Scott B, Wall A, Aquilonius $\mathrm{SM}$, et al. Evidence for astrocytosis in ALS demonstrated by [11C](L)-deprenyl-D2 PET. J Neurological Sci. 2007;255:17-22.

36. Schöll M, Carter SF, Westman E, Rodriguez-Vieitez E, Almkvist $\mathrm{O}$, Thordardottir $\mathrm{S}$, et al. Early astrocytosis in autosomal dominant Alzheimer's disease measured in vivo by multi-tracer positron emission tomography. Sci Rep. 2015;5:16404.

37. Rodriguez-Vieitez E, Saint-Aubert L, Carter SF, Almkvist O, Farid K, Scholl M, et al. Diverging longitudinal changes in astrocytosis and amyloid PET in autosomal dominant Alzheimer's disease. Brain. 2016;139:922-36. Pt 3

38. Carter SF, Chiotis K, Nordberg A, Rodriguez-Vieitez E. Longitudinal association between astrocyte function and glucose metabolism in autosomal dominant Alzheimer's disease. Eur J Nucl Med Mol Imaging. 2019;46:348-56.

39. Lemoine L, Saint-Aubert L, Nennesmo I, Gillberg P-G, Nordberg A. Cortical laminar tau deposits and activated astrocytes in Alzheimer's disease visualised by 3H-THK5117 and 3H-deprenyl autoradiography. Sci Rep. 2017;7:45496.

40. Lemoine L, Gillberg PG, Bogdanovic N, Nennesmo I, SaintAubert L, Viitanen M, et al. Amyloid, tau, and astrocyte pathology in autosomal-dominant Alzheimer's disease variants: A $\beta \mathrm{P}-$ Parc and PSEN1DE9. Mol Psychiatry. 2020. https://doi.org/10. 1038/s41380-020-0817-2.

41. Lin JS, Kitahama K, Fort P, Panula P, Denney RM, Jouvet M. Histaminergic system in the cat hypothalamus with reference to type B monoamine oxidase. J Comp Neurol. 1993;330:405-20.

42. Vitalis T, Fouquet C, Alvarez C, Seif I, Price D, Gaspar P, et al. Developmental expression of monoamine oxidases A and B in the central and peripheral nervous systems of the mouse. J Comp Neurol. 2002;442:331-47.

43. Tyacke RJ, Myers JFM, Venkataraman A, Mick I, Turton S, Passchier J, et al. Evaluation of (11)C-BU99008, a PET Ligand for the Imidazoline2 Binding Site in Human Brain. J Nucl Med. 2018;59:1597-602.

44. Li JX. Imidazoline I2 receptors: An update. Pharmacol Ther. 2017;178:48-56.

45. Tyacke RJ, Fisher A, Robinson ES, Grundt P, Turner EM, Husbands SM, et al. Evaluation and initial in vitro and ex vivo characterization of the potential positron emission tomography ligand, BU99008 (2-(4,5-dihydro-1H-imidazol-2-yl)-1- methyl$1 \mathrm{H}$-indole), for the imidazoline(2) binding site. Synapse. 2012;66:542-51.

46. Kealey S, Turner EM, Husbands SM, Salinas CA, Jakobsen S, Tyacke RJ, et al. Imaging imidazoline-I2 binding sites in porcine brain using 11C-BU99008. J Nucl Med. 2013;54:139-44.

47. García-Sevilla JA, Escribá PV, Walzer C, Bouras C, Guimón J. Imidazoline receptor proteins in brains of patients with Alzheimer's disease. Neurosci Lett. 1998;247:95-8.

48. Olmos G, Alemany R, Escriba PV, García-Sevilla JA. The effects of chronic imidazoline drug treatment on glial fibrillary acidic protein concentrations in rat brain. $\mathrm{Br} \mathrm{J}$ Pharmacol. 1994;111:997-1002.
49. Garcia-Sevilla JA, Escriba PV, Sastre M, Walzer C, Busquets X, Jaquet $\mathrm{G}$, et al. Immunodetection and quantitation of imidazoline receptor proteins in platelets of patients with major depression and in brains of suicide victims. Arch Gen Psychiatry. 1996;53:803-10.

50. Ruiz J, Martin I, Callado LF, Meana JJ, Barturen F, Garcia-Sevilla JA. Non-adrenoceptor [3H]idazoxan binding sites (I2-imidazoline sites) are increased in postmortem brain from patients with Alzheimer's disease. Neurosci Lett. 1993;160:109-12.

51. Parker CA, Nabulsi N, Holden D, Lin SF, Cass T, Labaree D, et al. Evaluation of 11C-BU99008, a PET ligand for the imidazoline2 binding sites in rhesus brain. $\mathrm{J}$ Nucl Med. 2014;55:838-44.

52. GraphPad Prism 8 for windows Version 8.3.0 (GraphPad software Inc., La Jolla, CA, USA).

53. Lenhossék M. Der feinere Bau des Nervensystems im Lichte neuester Forschung. Berlin:2nd Fischer's Medicinische Buchhandlung H Kornfield; 1895.

54. Verkhratsky A, Zorec R, Parpura V. Stratification of astrocytes in healthy and diseased brain. Brain Pathol. 2017;27:629-44.

55. Zhang Y, Barres BA. Astrocyte heterogeneity: an underappreciated topic in neurobiology. Curr Opin Neurobiol. 2010;20:588-94

56. Zamanian JL, Xu L, Foo LC, Nouri N, Zhou L, Giffard RG, et al. Genomic Analysis of Reactive Astrogliosis. J Neurosci. 2012;32:6391-410.

57. Matias I, Morgado J, Gomes FCA. Astrocyte Heterogeneity: Impact to Brain Aging and Disease. Front Aging Neurosci. 2019;11:59.

58. Oberheim NA, Takano T, Han X, He W, Lin JHC, Wang F, et al. Uniquely Hominid Features of Adult Human Astrocytes. J Neurosci. 2009;29:3276-87.

59. Gulyás B, Pavlova E, Kása P, Gulya K, Bakota L, Várszegi S, et al. Activated MAO-B in the brain of Alzheimer patients, demonstrated by [11C]-L-deprenyl using whole hemisphere autoradiography. Neurochemistry Int. 2011;58:60-8.

60. Habib N, McCabe C, Medina S, Varshavsky M, Kitsberg D, DvirSzternfeld R, et al. Disease-associated astrocytes in Alzheimer's disease and aging. Nat Neurosci. 2020;23:701-6.

61. Harada R, Hayakawa Y, Ezura M, Lerdsirisuk P, Du Y, Ishikawa Y, et al. ${ }^{18}$ F-SMBT-1: A Selective and Reversible PET Tracer for Monoamine Oxidase-B Imaging. J Nucl Med. 2021;62:253-8. https://doi.org/10.2967/jnumed.120.244400.

62. McDonald GR, Olivieri A, Ramsay RR, Holt A. On the formation and nature of the imidazoline I2 binding site on human monoamine oxidase-B. Pharmacol Res. 2010;62:475-88.

63. Bonivento D, Milczek EM, McDonald GR, Binda C, Holt A, Edmondson DE, et al. Potentiation of ligand binding through cooperative effects in monoamine oxidase B. J Biol Chem. 2010;285:36849-56

64. Kashon ML, Ross GW, O'Callaghan JP, Miller DB, Petrovitch H, Burchfiel CM, et al. Associations of cortical astrogliosis with cognitive performance and dementia status. J Alzheimer's Dis. 2004;6:595-604. discussion 73-81

65. Rodríguez JJ, Butt AM, Gardenal E, Parpura V, Verkhratsky A. Complex and differential glial responses in Alzheimer's disease and ageing. Curr Alzheimer Res. 2016;13:343-58.

66. De Vos H, Convents A, De Keyser J, De Backer J-P, Van Megen IJB, Ebinger G, et al. Autoradiographic distribution of $\alpha 2$ adrenoceptors, NAIBS, and 5-HT1A receptors in human brain using $[3 \mathrm{H}]$ idazoxan and $[3 \mathrm{H}]$ rauwolscine. Brain Res. 1991;566:13-20.

67. De Vos H, Bricca G, De Keyser J, De Backer JP, Bousquet P, Vauquelin G. Imidazoline receptors, non-adrenergic idazoxan binding sites and $\alpha 2$-adrenoceptors in the human central nervous system. Neuroscience. 1994;59:589-98. 
68. Nilsberth C, Westlind-Danielsson A, Eckman CB, Condron MM, Axelman K, Forsell C, et al. The 'Arctic' APP mutation (E693G) causes Alzheimer's disease by enhanced Abeta protofibril formation. Nat Neurosci. 2001;4:887-93.

69. Wilson H, Dervenoulas G, Pagano G, Tyacke RJ, Polychronis S, Myers $\mathrm{J}$, et al. Imidazoline 2 binding sites reflecting astroglia pathology in Parkinson's disease: an in vivo11C-BU99008 PET study. Brain. 2019;142:3116-28.

70. Malarte M-L, Nordberg A, Lemoine L. Characterization of MK6240, a tau PET tracer, in autopsy brain tissue from Alzheimer's disease cases. Eur J Nucl Med Mol Imaging. 2021;48:1093-102. 